\title{
Practical Issues of ERP-systems' Implementation-Russian Case
}

\author{
Kolganova Elena ${ }^{1,}$ a and Kolganov Aleksandr ${ }^{2}$, b \\ ${ }^{1} \mathrm{PhD}$, Management Department, Economic Faculty, RUDN University, Moscow, Russia; \\ ${ }^{2}$ PhD, Project Department, RZD Affiliated Company, Moscow, Russia. \\ ae_kolganova@mail.ru, bsashakolganov@yandex.ru
}

Keywords: ERP-System; Russian ERP Market; Implementation Risks; Budgeting Process; Business Process

\begin{abstract}
ERP-systems have already become an integral part of many businesses. But still companiesclients in most cases consider that ERP-system itself can solve all the organization problems. This does not correspond to reality. The purpose of this article is to prove that without thorough preparation taken by company-client the project can hardly become successful. Authors have conducted the analysis of eight different ERP-system implementation projects in Russia from their personal experience to find their main problems. This could not be done without the overview of the Russian ERP market. The article also presents main risks of ERP-system implementation. It was found that all the analyzed ERP-projects have common problems for solving of which the authors give their recommendations. The major recommendations concern increasing the probability of any ERP-system implementation project to be successful. These recommendations are given on the example of the budgeting process automatization in Russian transportation company. The article will be useful as for the companies-vendors and companiesclients as for the researches that make investigations in the ERP-system related spheres.
\end{abstract}

\section{Introduction}

On the July 10, 2018 the IDC presented the results of the Russian ERP-system market survey. According to it the volume of the Russian market of ERP-systems increased in USD in 2017 by $29.6 \%$ and amounted to $\$ 819.27 \mathrm{mln}$. In RUR in comparison with the previous year this indicator increased by $12.8 \%$. The leaders of the market are still SAP and 1C, which share in the whole investments into ERPsystems is more than $80 \%$. In addition, the SAP company finished the year 2017 with better results in Russia then in the previous five years. The gross profit increased by $33.2 \%$ in USD and $16 \%$ in RUR. The sales of $1 \mathrm{C}$ increased by $30 \%$ and by $13.2 \%$ consequently [1].

The main customers of the ERP-systems in Russia in accordance with IDC research stay the enterprises in production and retailing sectors of economy. The first group continues to implement new technologies in order to increase the effectiveness and security of production, the second group adjust their business-models under the increasing volumes of online-sales [1].

This situation on the market makes the theoretical and practical researches of ERP-systems' implementations in Russia very timely and actual.

\section{ERP-system Implementation Risks}

Many modern dynamic companies consider that ERP-system can solve their major problems only by the fact of its existence. But in fact, if the business processes in the company are not organized and defined properly the system will only deepen the problems and arise new ones.

In accordance with the Standish Group researches the share of successful projects in IT sphere (including ERP-system adoption) reached in 2015 only 29\% [2] and it fluctuated around 30\% since 2011. Previously this share was even much less. Despite the fact that the tendency is positive, the amount of IT projects implemented on time and on budget is still extremely low. And if the scale of projects is considered then the situation is even worse because among grand projects only less than 
$8 \%$ of projects are successful. For large and medium projects these figures are $13 \%$ and $14 \%$ consequently. For medium projects this figure reaches the average of 30\% and only the majority (70\%) of small projects are successful [2].

One of the reasons of this situation is obvious, it is the scale of the company and the project consequently. But large scale only detects the problems that are not so visible in other cases [3].

The process of ERP-system adoption especially in the large-scale companies can take several years. Taking into consideration quickly changing technical environment and aspiration of the companies to be innovative in order to win competition the process of ERP-system implementation and maintenance becomes permanent. The company-client and the company-vendor co-operate very closely for this period of time and share the majority of risks.

The authors have conducted the research of Russian ERP-systems projects both from the theoretical and practical points of view. All the conclusions are based on the personal experience and company and project analysis. Eight projects of different scale and in different industries from personal working experience were reviewed. And some common conclusions were made.

The main conclusion concerns the risks of ERP-system implementation. Among all the risks that are usually identified the following three groups seem to be the most influential for the analyzed projects:

- Project risks

- Financial risks

- Managerial Support risks

The first group is very wide and includes different issues of project management on one hand (wrong methods of project management (PM) or full denial of PM methodology, for example) and issues of project itself on the other hand. For instance, one of the main problems of the project in a large countryscale company in sphere of transportation was underdeveloped methodology of business processes building in the company which was to be provided by the client company. Firstly, it was given later than it was agreed, then it was modified several times during the process of implementation. That is a sort of human factor that includes tens of staff members and increases its impact consequently. The companyvendor rarely takes part in business processes evaluation and description. So, the risks of the project going wrong should always be kept in mind with the decision to include in time-resource plan extra time for unpredictable needs.

The second group concerns the risks of underfinancing. For the small and medium private companies this risk is concerned with the owners' internal motivation for ERP-system implementation. For stateowned companies or large-scale companies the problem is different - they may have budgets for different directions of development. These budgets are approved by the top-managers or the shareholders meetings, bureaucratic procedures are usually rather inflexible and the IT-director who is commonly in charge of the ERP-system implementation on the client side has to try to get the best service in the framework of the budget provided.

Underfinancing leads to such problems as unsuitable or incompetent vendors, partial implementation, not including all the necessary functions into the system being adopted. All of them can cause inappropriate work of the whole system. That is why the risks of underfinancing should be understood and implied on the stage of project initiation, discussing and methodology developing.

The third group of risks concerns the Managerial Support of the whole project from the client side. One of the significant problems of ERP-system implementation is resistance to change of the staff members who will do their day-to-day work using new system. It is a question of major importance for the company-client management to support the implementation and to be able to work with the staff to overcome this resistance. In one of the cases of ERP-system implementation in the nuclear power industry company the managers in charge of the project from the client's side were not interested in successful adoption due to their personal relations with each other. Until these managers were dismissed the project could not go further. This problem can hardly be solved by the company-vendor. If this risk 
triggered the only way is to negotiate and to try to involve the upper managers of the company-client into the problem solving.

\section{Practical Recommendations to ERP-System Adoption}

It seems appropriate to illustrate the mentioned risks on one of the projects from the analyzed portfolio. This project is part of the ERP-system implementation in one of the Russian country-scale companies in transportation industry. This project concerns budget management in the passenger transportation company subsidiary. It has been implementing for three years due to its wideness - tens of subsidiaries and very different budget forms that should have been implemented in the system. Recently the project is on the stage of maintenance. The main system is SAP but for some directions it was needed to be integrated with the historically used systems like MS Excel, 1CEnterprise (Russian system) etc. The analysis of this project showed the following results.

Automatization of the budgeting process itself cannot solve the organization problems as was mentioned above. Moreover, if the existing problems are not solved they can destroy whole ERP system and all the investments in fact will be wasted without any positive result.

Automatization of the process is mostly effective in case of routing tasks solving. These tasks either have already been settled in the company historically or they have been qualitatively structured. In this case human factor can be excluded by extrapolating of these settled structures into the ERP system and therefore building the rigid track for smooth process going under the discipline control.

The special attention should be drawn to the staff-members who make data consolidation and fills the forms. The specification of their work presumes the typical actions which can be optimized by the automatization. The time which is released as a result of automatization can be directed for analytics and strategic planning processes which need intellectual resources. One of the managers of the companyclient who is in charge of system implementation from their side answered the question about the expected results of the project. They expect the stable instrument for data aggregation which will give the possibility to create some new data and forms, then automatize this new process and so on in order to get the multiplicative effect in using and optimizing information.

As the examples of such tasks there could be presented:

- the processes of bringing the planned parameters to the direct task executor,

- procedures of coordinating and approving,

- filling in the factual values in the budget forms,

- gathering and consolidating of data among the company departments etc.

Before the initiating of the budgeting process automatization the following five factors should be considered [4]:

1. The system of budgeting process must be developed in the company-client. This system includes

- budget forms that are needed for proper resource management in the company;

- allocation of responsibility between departments for planned and factual data input in accordance with approved forms (budget owners). The principle of "one-in-charge" is fundamental in this case - for all the data in one form only one department can be responsible. This principle does not forbid the budget owner to ask the necessary data in other departments and responsibility centers, but for the data presence in the form only the budget owner must be responsible;

- regulations and guidance of filling in all the lines of the budgeting form with identification of the deadlines and those who is responsible for the process,

- methodology of needed indicators forming from the database including data sources and interrelations between different budget forms. 
The above-mentioned documents must be brought to the attention of all the members of budgeting process and clear to them. Otherwise the significant amount of time will be spent for resolving disputes between departments and in some cases this can cause the closure of the project.

2. The key departments personnel must be interested in their routine tasks automatization. If the employee is not interested or, that is worse, is against of the automatization than the project implementation will be sabotaged by the direct perpetrator. This will cause the development of deadlock requirements to the system, lingering process of optimal and sometimes roundabout solutions finding, the unnecessary add-ons forming and excessive developments, that leads to the solution weighting.

3. The company-client must define in advance all the range functions that is supposed to be automatized and make a clear and thorough description of them. Primarily it is necessary to do in order to control initiatives and create the clear limitations for the requirements because overstated expectations lead to many problems in the system implementation process. In particular overstated expectations lead to exaggerated requirements which decrease the transparency of the final results vision and demand additional resources and specialists and thus blur the responsibility.

4. As a result the ERP-system can swell to enormous size and include the range of unrelated (and thus not working properly) functional that decreases the system productivity and significantly complicates its architecture on the whole.

5. This problem can be solved by the competent project director that clearly understands the organizational structure of the process and each its section. this person should be interested (see factor 2) in the project, have the necessary authority and resources in order to eliminate exceeding initiative and keep the project in actual condition.

6. The company-client must timely develop the order of the budgeting process and internal management reporting and relations of this order to the financial accounts data. In case the company has the sufficient level of accounting and internal management reporting systems automatization than it can be presumed that raw data is already entered into the ERP-system. Then the methodology of its transformation into the internal management reports is left to be developed. Consequently, the budget forms must be developed in accordance with this information.

7. Any automatization creates a base and locks the process into the rigid framework of obligation and changelessness but with possibility of sensible correction it is needed. That is why if the process presumes on some stages variability of actions or sort of creativity in data analysis and interpretation then these processes must be left beyond the ERP-system and outside the object of automatization. These processes must be realized by the relevant personnel and for the ERPsystem the tasks of data calculating and storage must be left.

Basing on these conclusions the internal regulations for the company-vendor were developed in order to be used for the future projects.

\section{Conclusion}

In any case it is significant to keep in mind that any automatization and ERP-system adoption involves investments. As any investment activity they should be planned and thought over. The more ambitious the project the more investments will it demand, the more organizational changes will it involve. But the investments should be adequate and commensurable to the expected project effect.

The competent and interested team in the company-client that clearly understands the expected final result significantly decreases the range of unexpected tasks and as a result positively influences the costs and duration of the project letting it to become successful (on-time and on-budget). Moreover, such 
project with high level of probability will not become unbearable for the direct executors as the natural resistance to changes will be overcome in advance.

The companies-clients should keep in mind that vendors can offer solutions only for clearly defined and descripted tasks.

The authors expect that the results of this survey will be useful for all the companies (vendors, clients, analysts etc.) which work with ERP-systems and can help to increase the share of successful projects.

\section{Acknowledgment}

The publication was prepared with the support of "RUDN University Program 5-100".

\section{References}

[1]. Systems of Enterprise Resource Planning, Russian Market. The article is a part of Russian Market of ERP-systems Review. http://www.tadviser.ru/index.php/ERP

[2]. Standish Group 2015 Chaos Report - Q\&A with Jennifer Lynch. Posted by Stéphane Wojewoda, Shane Hastie on Oct 04, 2015. https://www.infoq.com/articles/standish-chaos-2015

[3]. V.S. Efremov, I.G. Vladimirova, Crisis of the Management Paradigm - is there light at the end of the tunnel? Advances in the Social Science, Education and Humanities Research (ASSEHR) 2017, p. 1-4

[4]. A. Kolganov Internal Regulations for ERP project management. Unpublished. 